\title{
Dynamic of Metabolic Indicators, Insulin Like-growth Factor I (IGF-I) and Cortisol in Holstein Cows during the Transition Period
}

\author{
Vinicius Alvim Passos Baldacim ', Karina Medici Madureira², Jean Silva Ramos', \\ Cynthia Pereira da Costa e Silva', Clara Satsuki Mori', Maylson Rennan Borges Dias' \& Viviani Gomes'
}

\begin{abstract}
Background: Physiological events occur in the transition period marked by negative energetic balance, where the energetic demand is higher due to fetal nutrition and lactogenesis and intensified by the decrease of the dry matter intake in the pre-partum period. The adaptation of cows is dependent of homeostatic and homeorhetic mechanisms regulated by catecholamine, cortisol, GH, IGF-I, insulin and glucagon but the priorization of homeorhetic mechanisms could result in metabolic diseases. Considering the scarce longitudinal studies about the Brazilian conditions the aim of this project was to evaluate the influence of transition period on metabolic indicators, cortisol and IGF-I in Holstein cows.

Materials, Methods \& Results: Thirteen cows, from 2nd to 4th lactation were evaluated weakly from week -2 to week +3 in relation to calving to determine the body condition score (BCS), metabolic and endocrine profile. The BCS decreased between week $-2(\mathrm{BCS}=4.0)$ and $+1(\mathrm{BCS}=3.0)$, followed by and slight increase on weeks +2 and $+3(P=0.000)$. The most of metabolic indicators and hormones have changed during the transition period $(P \leq 0.05)$, especially around calving. It was possible to detect the peak of cortisol, glucose, non-esterified fatty acids (NEFA), B-hydroxibutyrate (BHB), and aspartate aminotransferase (AST) on delivery and week +1 . On the other hand, total calcium, triglycerides (TG) and cholesterol (CHOL) decreased was observed around parturition. Insulin like growth factor type I (IGF-I) showed marked reduction between pre and postpartum, and the lowest value was observed in the week +1 . TP and GLOB had the lowest value on calving and globulin has a gradual increase from delivery to week +3 .

Discussion: Cows included in this experiment had dystocia $(4 / 13,30.8 \%)$, retention of placenta $(1 / 13,7.7 \%)$ and clinical hypocalcemia $(1 / 13,7.7 \%)$. One of the animals with episodes of dystocia was also aggravated by ketosis in week +1 and $+2(1 / 13,7.7 \%)$. Uterine infections were observed in five animals $(5 / 13,38.4 \%)$. Of this total of animals with uterine infection (5/13), three had already expressed earlier disturbances: two cows had dystocia and one cow with retention of placenta. The weight loss observed between pre and postpartum may be due to an increase of energy demand for fetal maintenance and the concomitant initiation of lactation, in conjunction with an approximately $30 \%$ reduction in dry matter intake during the transitional period. The hyperglycemia concomitant with the peak of cortisol at delivery may be explaining by the activation of the somatotropic axis, due to the stress of calving. The increase of NEFA, BHB and AST around calving associated with decreased of TG and CHOL could be associated with homeorhetic mechanisms, especially lipolysis and gluconeogenesis. The IGF-I decrease in postpartum may be by the decreased expression of receptors for growth hormone $(\mathrm{GH})$ in the liver, and consequently reduced synthesis and/or IGF-I hepatic clearance, which reduce of the negative feedback of IGF-I on GH secretion. The total calcium concentrations were below the threshold $(8.50 \mathrm{mg} / \mathrm{dL})$ established by Goff [10] at parturition, week +1 and +2 and probably is due to the secretion of 20-30 $\mathrm{g}$ of calcium per day during the colostrum synthesis. Total protein and albumin have a slight variation, except for the peak observed on week +3 due to uterine infection.
\end{abstract}

Keywords: body condition score, non-esterified fatty acids, $\beta$-hydroxibutyrate, total calcium, hormones. 


\section{INTRODUCTION}

In recent decades, dairy management systems have used genetic selection to increase the productivity of cattle resulting in higher metabolic demand and immunosuppression [13]. The potential consequences of this process are intensified in the transition period due to fetal nutrition and lactogenesis [12]. In this phase, the generation and distribution of energy will depend on the homeostatic and homeorrhetic mechanisms regulated by catecholamines, cortisol, IGF-I, insulin and glucagon [9].

Dairy cattle have been selected to re-partition nutrients to support milk production in which homeostatic mechanisms are at least partially and overridden, including a period of insulin resistance and promoting elevation of NEFA and BHB [16]. The protein profile may also change due to the consumption of amino acids in gluconeogenesis [6]. Calcium demand increases due to the production of colostrum and milk, which can result in hypocalcemia and an increased risk for displaced abomasum and retained placenta [10].

The metabolites from lipolysis and hypocalcemia, as well dramatic changes in circulating progesterone, estrogen, cortisol, GH and IGF-I concentration contributes to a substantial reduction of the immune function which increases the risk of diseases [16]. This cascade of interconnected events seems to be triggered by metabolic imbalance, however, there are few studies that have evaluated the interactions between metabolic and hormonal dynamics through time; which motivated this longitudinal study whose objective was to evaluate the influence of transition period on metabolic indicators, IGF-I and cortisol in Holstein cows.

\section{MATERIALS AND METHODS}

\section{Animals and conditions of study}

This study was approved by the Ethics Committee on animal use (FMVZ-USP) protocol number 2767/2012. Thirteen Holstein cows from second to fourth parity were included in this research. The study was conducted between September to November 2013 in the Paulista Agency of Agribusiness Technology (APTA) - Dairy Cattle, located in Nova Odessa, São Paulo, latitude $22^{\circ} 75^{\prime} \mathrm{S}$ and longitude $47^{\circ} 27^{\prime} \mathrm{W}$.

The conditions and management routine adopted by the farm were maintained in this study. The cows were transferred to the collective maternity pen 30 days before expected calving date, where they had access to pasture (coast cross e tifton), hay $(0.3 \mathrm{~kg})$, corn silage with $43 \%$ of dry matter $(20 \mathrm{~kg})$, and concentrate (3 $\mathrm{kg}$ ) twice a day. The concentrate was produced in the APTA feed mill, and it was made up of whole ground corn $(69 \%)$, soybean meal $(27 \%)$, mineral and vitamin core $(3 \%)$ and protein salt $(1 \%)$. Minerals and vitamins were added in the manufacture of feed and mineral salt and water were provided ad libitum.

From parturition, each cow was transferred to newly calved cows barns and received the same prepartum diet but in different quantities depending on their milk production: $35 \mathrm{~kg}$ of corn silage and 1 $\mathrm{kg}$ of concentrate per kilo of milk produced.

The chemical composition of the total diet was sampled once during pre and once during postpartum and the diet was formulated as requirements recommended by NRC [20] and was composed of 11.6 and $17.9 \%$ of crude protein; 18.8 and $11.4 \%$ of crude fiber; 1.8 and $1.8 \%$ of ether extract; 3.5 and $4.1 \%$ of mineral matter; 64.3 and $64.9 \%$ of nitrogen-free extract; 24.4 and $101 \mathrm{~g}$ of calcium and 27.3 and $143.6 \mathrm{~g}$ of phosphorus, respectively.

Regarding the welfare conditions of the cows, it was observed the absence of coverage in the maternity pen, except for the existence of some trees, no specific areas for calving and it was not attended at night. The anionic balance of the diet was not considered due to the allegation of low rates for hypocalcemia and retention of placenta.

The animals were evaluated weekly, from the second week before calving to the third week postpartum and were classified according to the following times: week -2 , week -1 , calving (zero to $12 \mathrm{~h}$ after calving), week +1 , week +2 and week +3 . The body condition score (BCS) was evaluated once per week, before the blood collection and it was determined according to Edmonson et al. [8]. Data regarding diseases during the period of this experiment were obtained through property records.

\section{Samples and parameters}

Blood samples $(n=78)$ from the 13 cows were obtained once per week, from week -2 to +3 . Samples were collected from coccygeal vein punctures into tubes containing sodium fluoride and no anticoagulants. Biochemical tests were performed with an automatic analyzer (Randox Rx Daytona Chemistry Analyzer $\left.{ }^{\mathrm{TM}}\right)^{1}$ using commercial kits: glucose, non- 
-esterified fatty acids - NEFA, Beta hydroxybutyrate - BHB, triglycerides - TG, cholesterol - CHOL, total protein - TP, albumin - ALB, aspartate aminotransferase - AST, gamma glutamyl transferase - GGT and total calcium.

The globulin (GLOB) was determined by the difference between serum TP and ALB, the ratio albumin:globulin (ALB:GLOB) was calculated to obtain an indicator of liver damage $(<0.5-[14])$, and the concentration of circulating ionized calcium $\left(\mathrm{Ca}^{++}\right)$was estimated using the formula given by Barreto Junior [2], where $\mathrm{Ca}^{++}=6 \mathrm{Ca}$ (total) $-(\mathrm{TP} / 3), \mathrm{TP}+6$.

Serum cortisol (Immulite/Immulite $1000^{\circ}$ Cortisol $)^{2}$ and insulin-like growth factor I - IGF-I (Immulite/Immulite $1000^{\circ}$ IGF-1) ${ }^{2}$ were measured with immunoassay tests that implemented the chemiluminescence method using a commercial kit.

\section{Statistical analysis}

Statistical analysis was performed using SPSS 17.0. First, all variables at all times were tested for adherence to the normal distribution using the Shapiro Wilk test, performing after that nonparametric tests. The small number of animals also favored nonparametric tests. Dependent samples with quantitative values were analyzed using the Friedman test to evaluate the difference between time intervals and revealing at least one significantly different time interval, multiple comparisons were conducted using the Wilcoxon test with the Bonferroni correction (post-hoc analysis), using $\alpha$ $=0.003$ for blood parameters.

\section{RESULTS}

The occurrence of diseases was observed by farm team from parturition. It was detected four episodes of dystocia $(4 / 13,30.8 \%)$, one case of retention of placenta $(1 / 13,7.7 \%)$ and one case of clinical hypocalcemia $(1 / 13,7.7 \%)$. One of the animals with episode of dystocia were also aggravated by ketosis in week +1 and $+2(1 / 13,7.7 \%)$. Uterine infections were observed in five animals $(5 / 13,38.4 \%)$ : week $+1(1 / 13,7.69 \%)$, $+2(4 / 13,30.8 \%)$ and $+3(2 / 13,15.3 \%)$. Of this total of animals with uterine infection (5/13), three had already expressed earlier disturbances: two cows had dystocia and one cow with retention of placenta.

The BCS changed during the transition period according to Friedman test $(P=0.000)$, decreasing from the week $-2(\mathrm{ECC}=4.0)$ to $+1(\mathrm{ECC}=3.0)$, but increasing to 3.5 in subsequent time intervals
(Figure 1A). Wilcoxon associated with Bonferroni test demonstrated difference between week -1 and $+1(P=0.003)$.

The median glucose levels increased from week $-2(67.8 \mathrm{mg} / \mathrm{dL})$ until reach the peak at calving $(85.0 \mathrm{mg} / \mathrm{mL})$, then the values decreased and remained stable $(P=0.001)$ [Figure 1B]. The comparison between times demonstrated differences between calving and $+2(P=0.003)$.

The NEFA increased from week -2 $(0.132$ $\mathrm{mmol} / \mathrm{L})$ to $+1(0.712 \mathrm{mmol} / \mathrm{L})$, then the values decreased in the subsequent weeks $(P=0.011)$ [Figure $1 \mathrm{C}$ ]. The time analysis demonstrated difference between week -2 and calving, $+1,+2$ and $+3(P \leq 0.003)$. A difference was also observed between calving when compared with $+2(P=0.003)$ and $+3(P=0.002)$. The values from week +1 were also difference those obtained on week $+3(P=0.003)$.

The BHB levels showed changes similar to NEFA, increasing from week $-2(0.543 \mathrm{mmol} / \mathrm{L})$ to $+1(0.737 \mathrm{mmol} / \mathrm{L})$, however, no differences were observed between time intervals using Friedman test $(\alpha>0.003)$ [Figure 1D].

TG concentrations changed during the transition period $(P=0.000)$. High values was detected on week -2 (15.4 mg/dL) and -1 (20.5 mg/dL), observing a decrease in subsequent moments (Figure 1E). Time-analysis demonstrated differences between week -1 and calving, $+1,+2$ and $+3(P \leq 0.003)$. CHOL levels decreased from prepartum $(81.8 \mathrm{mg} / \mathrm{L})$ to calving $(75.2$ $\mathrm{mg} / \mathrm{L})$ and $+1(71.6 \mathrm{mg} / \mathrm{L})$, after the values increased in subsequent time intervals $(P=0.000)$ [Figure $1 F$ ]. The time analysis demonstrated differences between week +3 and -1 , calving, +1 and $+3(P \leq 0.003)$ and between week -1 and calving $(P=0.003)$.

IGF-1 decreased from the week -2 (112.0 ng/ $\mathrm{mL})$ to calving $(25.2 \mathrm{ng} / \mathrm{mL})$, with stability until week $+2(25.0 \mathrm{ng} / \mathrm{mL})$, and an increase in $+3(45.0 \mathrm{ng} / \mathrm{mL})$ $[P=0.000]$ (Figure 1G). Differences were detected between values in week +1 and $-2(P=0.003)$, as well as week -1 and $+1,+2$ and $+3(P=0.003)$, using the post-hoc test.

Cortisol serum concentrations remained stable during the period, except during calving $(1.98 \mu \mathrm{g} / \mathrm{dL})$ and $+3(1.64 \mu \mathrm{g} / \mathrm{dL})$, where maximum values were observed $(P=0.009)$ [Figure $1 \mathrm{H}]$. Time analysis detected differences between parturition and week $-2(P=0.002)$. 
The concentration of total calcium fluctuated between -2 and $+3(P=0.000)$, increasing from -2 to -1 , observing lowest levels on calving $(8.10 \mathrm{mg} / \mathrm{dL})$. After, the levels had a slight increase in the subsequent moments $(8.9 \mathrm{mg} / \mathrm{dL})$ [Figure 2A]. Multiple comparisons detected differences between week -1 compared with -2 , calving, $+1,+2$ and $+3(P \leq 0.003)$.

The indicators of protein profile changed during the period according to Friedman test $(P \leq 0.05)$. TP and GLOB variations were similar, with the lowest value occurring during calving ( $\mathrm{TP}=6.19$ and GLOB $=2.64 \mathrm{~g} / \mathrm{dL}$ ), and the maximum value observed at +3 $(\mathrm{TP}=7.28$ and $\mathrm{GLOB}=4.14 \mathrm{~g} / \mathrm{dL})$ [Figure $2 \mathrm{~B}$ and $2 \mathrm{C}]$. Time analysis demonstrated differences between +3 compared with $-2,-1$, calving, +1 and $+2(P \leq 0.003)$ for TP and GLOB.

The ALB levels decreased in the postpartum period (3.60-3.20 g/dL) $[P=0.000]$, but no differences were observed using the post hoc test (Figure 2D). The albumin:globulin (Figure 2E) ratio showed variations during the study period $(P=0.000)$. The values increased from week -2 to calving $(P=0.000)$, observing a gradual decrease in the ratio in the subsequent moments. The multiple comparisons between times demonstrated differences between week -2 and calving compared with +2 and $+3(P \leq 0.003)$ and between week -1 and $+2(P=0.003)$.

The enzymatic activity of the AST increased from week -2 (48.43 U/L) to +1 (69.32 U/L), with a reduction of the values in subsequent periods (58.77$58.64 \mathrm{U} / \mathrm{L} ; P=0.000$ ) [Figure $2 \mathrm{~F}$ ]. Time analysis detected differences between week -2 compared with calving and $+1(P=0.003)$. Differences was also observed between week -1 and calving $(P=0.002)$. However, no differences were observed in GGT activity between the periods $(P=0.096)$ [Figure $2 \mathrm{G}$ ].

\section{DISCUSSION}

This study evaluated the metabolic profile in Holstein cows during the transition period. The cows started the experiment with high BCS in prepartum (4.0), but reduced to 3.0 at week $+1(\Delta=-1.0)$ and 3.5 in +2 and $+3(\Delta=+0.5)$. Mouffok et al. [19] observed reduction in BCS from 3.04 to $2.77(\Delta=-0.27)$ between weeks -6 to +6 . The various BCS in prepartum may have determined the intensity of weight loss in these studies [15]. According to Drackley et al. [7], the weight loss observed between pre and postpartum may be due to an increase of energy demand for fetal maintenance, the concomitant initiation of lactation and a reduction in approximately $30 \%$ of dry matter intake during the transitional period.

The amount of glucose changed only during calving, observing hyperglycemia $(85.05 \mathrm{mg} / \mathrm{dL})$ concomitant with the peak of cortisol. Hammon et al. [11] also found a maximum glucose concentration during parturition $(72 \mathrm{mg} / \mathrm{dL})$. This phenomenon may be due to the activation of the somatotropic axis, due to the stress of calving that results in the release of hyperglycemic hormones cortisol and catecholamines [22].

Variations in metabolism occurred during calving and week +1 ; we observed an increase in the values of NEFA and BHB, associated with decreased of TG and CHOL. Changes in energetic indicators measured in this study were consistent with those described by Hammon et al. [11] and Alvarenga et al. [1] who both observed increases in plasma levels of NEFA (1.0 and $0.44 \mathrm{mmol} / \mathrm{L})$ and $\mathrm{BHB}(1.25$ and $0.68 \mathrm{mmol} / \mathrm{L})$ during calving. This phenomenon can be associated with homeorhetic mechanisms, especially lipolysis and gluconeogenesis, to increase the availability of energy and supply the demand for colostrum synthesis and lactation [5]. In this research the concentrations of NEFA were higher than the previously reported risk factor thresholds of $0.4 \mathrm{mmol} / \mathrm{L}$ (prepartum) and 0.7 $\mathrm{mmol} / \mathrm{L}$ (postpartum); which indicate higher risks of production diseases in the transition period [3].

The reduction of CHOL and TG concentrations during parturition and week +1 was also related to the reduction in food intake, reduction in insulin, and increase in glucagon concentrations [1]. Consequently, there is an increase in glucose and cortisol in the same period, as also observed in this study.

IGF-I showed marked reduction between pre (8.67-11.20 mg/L) and postpartum (2.50-4.50 mg/L), and the lowest value was observed in the week +1 $(2.50 \mathrm{mg} / \mathrm{L})$. The IGF-I decrease in postpartum was also reported by Hammon et al. [11]. In the immediate postpartum period there was a decreased expression of receptors for $\mathrm{GH}$ in the liver, and consequently, reduced synthesis and/or IGF-I hepatic clearance, which reduce negative feedback of IGF-I on GH secretion [17]. Elevated GH levels during the negative energy balance (NEB) that occurred in peripartum exacerbate lipolysis and production of NEFA. 

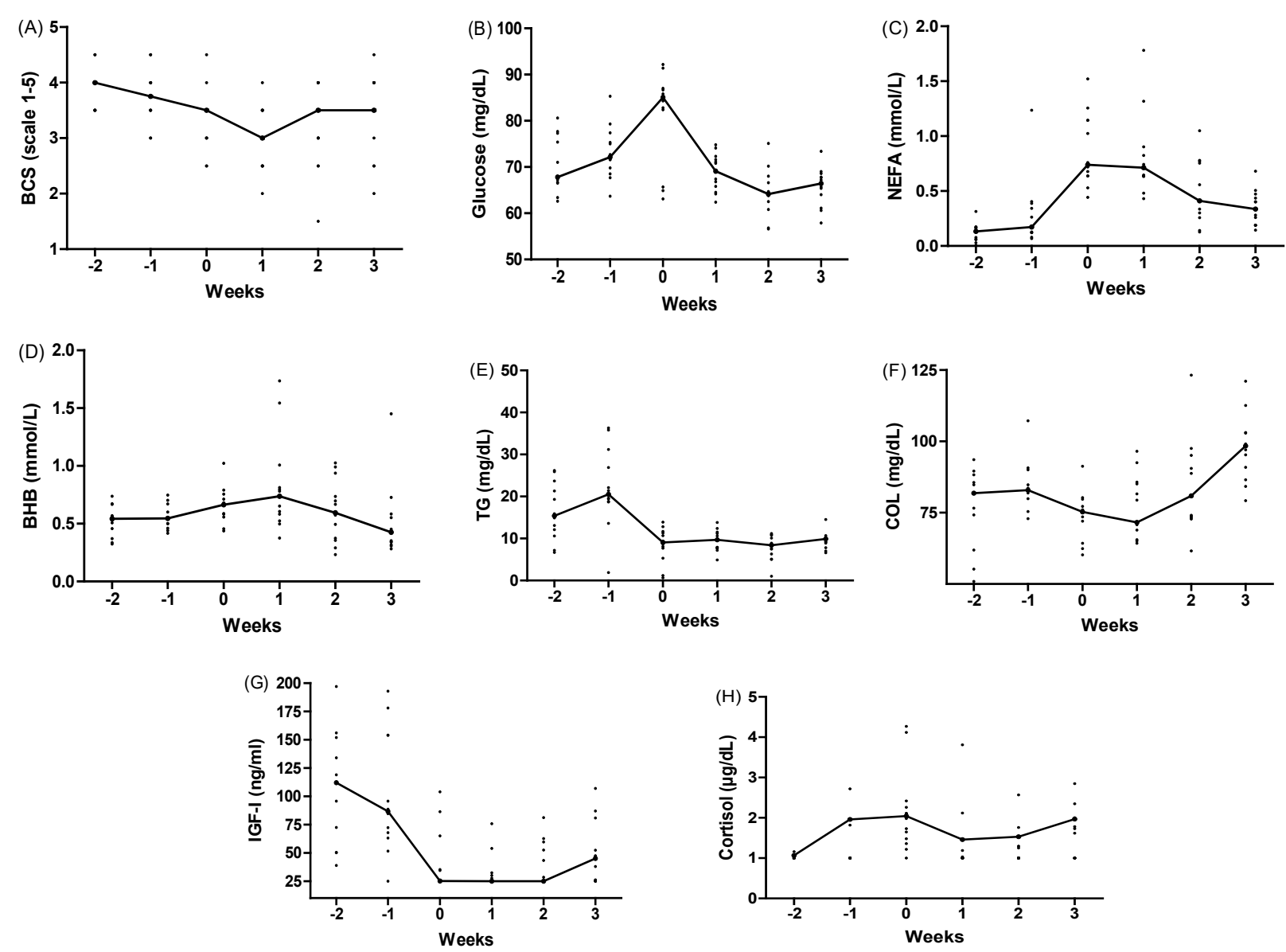

Figure 1. Median values for body condition score (BCS), indicators of energy profile, blood IGF-I and cortisol in Holstein cows during the transition period.

The total calcium concentrations of transition cows were below the threshold $(8.50 \mathrm{mg} / \mathrm{dL})$ established by Goff [10] at parturition $(8.10 \mathrm{mg} / \mathrm{dL})$, week $+1(8.35 \mathrm{mg} / \mathrm{dL})$ and $+2(8.30 \mathrm{mg} / \mathrm{dL})$. However, only one animal in this study showed clinical features of hypocalcemia after calving. The profile found for total calcium is due to the secretion of 20-30 g of calcium per day during the colostrum synthesis [10]. Hypocalcemia has been associated with low milk production, low conception rates in the first artificial insemination, and high risks for displaced abomasum and retention of placenta [3].

Hypoproteinemia due hypoalbuminemia observed in this study may be related to a decrease in hepatic biosynthesis by the presence of ketone bodies in hepatocytes [23] and the decrease of ALB may result from an increase in the utilization of amino acids in gluconeogenesis near parturition. The increase of AST during the studied period corroborates this hypothesis since this enzyme is a significant indicator of protein catabolism [24].
The second oscillation observed for TP occurred at week +3 and it was associated with the second peak of cortisol and increased levels of GLOB. These changes may be related to the presence of uterine infections affecting two of the 13 cows during this period.

The cows analyzed in this study had a high BCS in prepartum (4.0), with a great loss of body weight in week $+1(\Delta=-1.0)$. In addition, high levels of NEFA and BHB indicate an intense NEB, which together with low concentrations of calcium, total proteins and albumin may have contributed to the manifestation of the diseases reported here. Considering the cutoff point of $0.7 \mathrm{mmol} / \mathrm{L}$ for NEFA [3], it was verified that $69.2 \%(9 / 13)$ of the animals used in this study had values higher than the cutoff point in the first two weeks after calving. For BHB, the prevalence was $100 \%$ and $69.2 \%(9 / 13)$, considering the cut-off points of 0.41 (prepartum) and $0.68 \mathrm{mmol} / \mathrm{L}$ (postpartum) [18]. BHB is the most important indicator of NEB and the amount produced is directly linked to the intensity of mobilization of NEFA [21]. 

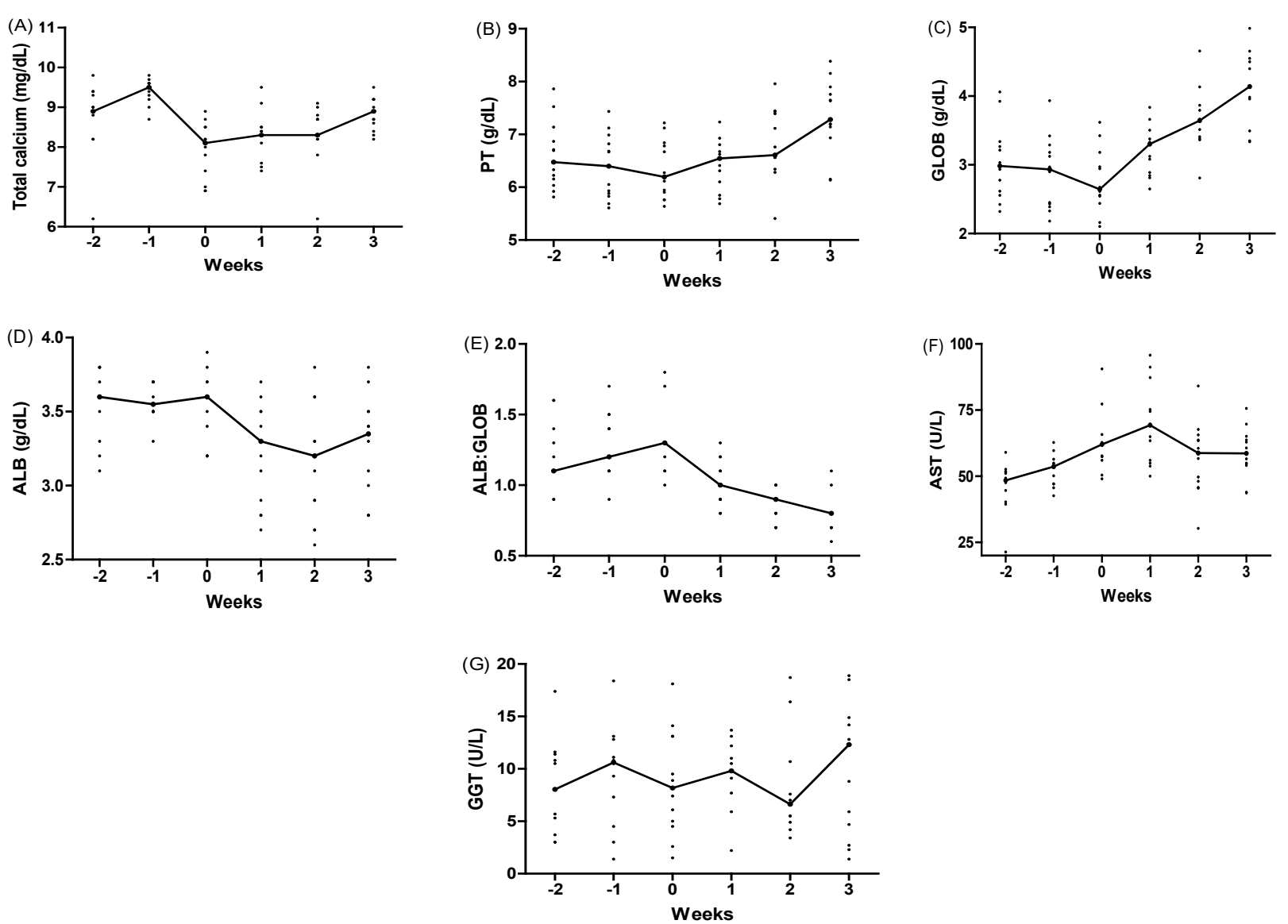

Figure 2. Median values for total calcium, indicators of proteins and liver enzymes in Holstein cows during the transition period.

The highest concentration of NEFA and the lowest TP value at parturition was also observed in this study, probably caused by fat infiltration and hepatic impairment due to the high lipid mobilization. Corassin et al. [4] verified that cows with BCS above 4.0 at calving had 1.48 times more chances of developing ketosis.

In this study some factors linked to the management conditions offered to the cows at prepartum allowed us to identify some risk factors, that together with the blood parameters obtained may have contributed to the high rate of diseases in the herd: 1 . Welfare - this research was conducted in warm months of the year (spring and summer), the shade area in the pre-partum pen was scarce, there was no management or specific area that provided conditions that favored the privacy and comfort of the cows during calving. The deliveries were not attended at night and weekends, providing delay in obstetric assistance. These events may have intensified the stress of cows around calving and justify the cortisol peak observed in this period; 2. Regarding the diet of cows it was verified that the calcium and phosphorus ratio is unbalanced, being one of the factors that may have contributed to the occurrence of clinical hypocalcemia. Subclinical hypocalcemia was present throughout the study period, with a higher prevalence (approximately 70\%) at calving and week +1 . Thus, the risk factors present in the rearing system contributed to the high rate of diseases observed from calving.

Considering the health profile presented by the cows, it is possible to predict that the metabolic and hormonal dynamics observed during the transition period were influenced by interconnected events, such as NEB, stress around calving (cortisol peak) and high rate of diseases from calving.

\section{CONCLUSIONS}

The results obtained in this study demonstrate that the most of metabolic indicators and hormones have changed during the transition period. The peak of cortisol, glucose, NEFA, BHB and AST was on calving and week +1 , but total calcium, TG, CHOL and the protein profile decreased around parturition. IGF-I 
showed marked reduction between pre and postpartum, and the lowest value was observed in the week +1 .

\section{MANUFACTURERS}

${ }^{1}$ Randox Laboratories Ltd. Kearneysville, WV, USA.

${ }^{2}$ Siemens Healthcare Diagnostics. Tarrytown, NY, USA.

Funding. This research was supported by grants from National
Counsil for Cientific and Technological Development (CNPq; Project number 479381/2013).

Ethical approval. The Ethics Committee on animal use at FMVZ-USP (number 2767/2012) approved this study.

Declaration of interest. The authors report no conflicts of interest. The authors alone are responsible for the content and writing of paper.

\section{REFERENCES}

1 Alvarenga E.A., Moreira G.H.F.A., Facury Filho E.J., Leme F.O.P., Coelho S.G., Molina L.R., Lima J.A.M. \& Carvalho A.U. 2015. Avaliação do perfil metabólico de vacas da raça Holandesa durante o período de transição. Pesquisa Veterinária Brasileira. 35(3): 281-290.

2 Barreto Junior R.A. 2007. Estudo de um modelo experimental de indução e tratamento de hipocalcemia em bovinos e equinos. 95f. São Paulo, SP. Tese (Doutorado em Clínica Veterinária) - Programa de Pós-graduação em Clínica Veterinária, Universidade de São Paulo.

3 Chapinal N., Carson M., Duffield T.F., Capel M., Godden S., Overton M., Santos J.E.P. \& Leblanc S.J. 2011. The association of serum metabolites with clinical disease during the transition period. Journal of Dairy Science. 94(10): 4897-4903.

4 Corassin C.H., Machado P.F., Coldebella A., Cassoli L.D. \& Soriano S. 2011. Importância das desordens do periparto e seus fatores de risco sobre a produção de leite de vacas Holandesas. Semina. 32(3): 1101-1110.

5 Drackley J.K. 1999. Biology of dairy cows during the transition period: the final frontier? Journal of Dairy Science. 82(11): 2259-2273.

6 Drackley J.K., Overton T.R. \& Douglas G.N. 2001. Adaptations of glucose and long-chain fatty acid metabolism in liver of dairy cows during the periparturient period. Journal of Dairy Science. 84(E.suppl): E100-E112.

7 Drackley J.K., Dann H.M., Douglas G.N., Guretzky N.A.J., Litherland N.B., Underwood J.P. \& Loor J.J. 2005. Physiological and pathological adaptations in dairy cows that may increase susceptibility to periparturient diseases and disorders. Italian Journal of Animal Science. 4: 323-344.

8 Edmonson A.J., Lean I.J., Weaver L.D., Farver T \& Webster G. 1989. A body condition scoring chart for Holstein dairy cows. Journal of Dairy Science. 72(1): 68-78.

9 Graber M., Kohler S., Kaufmann T., Doherr G., Bruckmaier R.M. \& van Dorland H.A. 2010. A field study on characteristics and diversity of gene expression in the liver of dairy cows during the transition period. Journal of Dairy Science. 93(11): 5200-5215.

10 Goff J.P. 2004. Macromineral disorders of the transition cow. Veterinary Clinics of North America Food Animal Practice. 20: 471-494.

11 Hammon H.M., Sturmer G., Schneider F., Tuchscherer A., Blum H., Engelhard T., Genzel A., Staufenbiel R. \& Kanitz W. 2009. Performance and metabolic and endocrine changes with emphasis on glucose metabolism in highyielding dairy cows with high and low fat content in liver after calving. Journal of Dairy Science. 92(4): 1554-1566.

12 Hayirli A., Grummer R.R., Nordheim E.V. \& Crump P.M. 2002. Animal and dietary factors affecting feed intake during the prefresh transition period in Holsteins. Journal of Dairy Science. 85(12): 3430-3443.

13 Ingvartsen K.L. \& Moyes K. 2013. Nutrition, immune function and health of dairy cattle. Animal. 7(s1): 112-122.

14 Kaneko J.J., Harvey J.W. \& Bruss M.L. 2008. Clinical Biochemistry of Domestic Animals. 6th edn. San Diego: Academic Press, 936 p.

15 Lake S.L., Scholljegerdes E.J., Atkinson R.L., Nayigihugu V, Paisley S.I., Rule D.C., Moss G.E., Robinson T.J. \& Hess B.W. 2005. Body condition score at parturition and postpartum supplemental fat effects on cow and calf performance. Journal of Animal Science. 83(12): 2908-2917.

16 Leblanc S. 2010. Monitoring metabolic health of dairy cattle in the transition period. Journal of Reproduction and Development. 56(Suppl): 29-35.

17 Mendonça L.G.D., Litherland N.B., Lucy M.C., Keisler D.H., Ballou M.A., Hansen L.B. \& Chebel R.C. 2013. Comparison of innate immune responses and somatotropic axis components of Holstein and Montbéliarde-sired crossbred dairy cows during the transition period. Journal of Dairy Science. 96(6): 3588-3598. 
18 Moreira T.F. 2013. Perfil metabólico de vacas leiteiras no período de transição em sistema semi-intensivo em Minas Gerais no verão e no inverno. 123f. Belo Horizonte, MG. Dissertação (Mestrado em Ciência Animal) - Programa de Pós-graduação em Ciência Animal, Universidade Federal de Minas Gerais.

19 Mouffok C.E., Madani T., Semara L., Ayache N. \& Rahal A. 2013. Correlation between body condition score, blood biochemical metabolites, milk yield and quality in Algerian Montbéliarde cattle. Pakistan Veterinary Journal. 33(2): 191-194.

20 National Research Council. 2001. Nutrient requeriments of dairy cattle. 7 th edn. Washington: The National Academies Press, 381p.

21 Ospina P.A., Nydam D.V., Stokol T. \& Overton T.R. 2010. Evaluation of nonesterified fatty acids and $\beta$-hydroxybutyrate in transition dairy cattle in the northeastern United States: Critical thresholds for prediction of clinical diseases. Journal of Dairy Science. 93(2): 546-554.

22 Patel O.V., Takahashi T., Takenouchi N., Hirako M., Sasaki N. \& Domeki I. 1996. Peripheral cortisol levels throughout gestation in the cow: effect of stage of gestation and fetal number. The British Veterinary Journal. 152(4): 425-432.

23 Samanc H., Kirovski D., Stojic V., Stojanovic D., Vujanac I., Prodanovic R. \& Bojkovic-Kovacevik S. 2011. Application of the metabolic profile test in the prediction and diagnosis of fatty liver in Holstein cows. Acta Veterinaria. 61(5-6): 543-553.

24 Seal C.J. \& Reynolds C.K. 1993. Nutritional implications of gastrointestinal and liver metabolism in ruminants. Nutrition Research Reviews. 6(1): 185-208. 